\title{
Trends in Inpatient versus Outpatient Anterior Cervical Discectomy and Fusion in the United States of America: An Epidemiologic and Economic Analysis
}

\author{
FJR Pencle ${ }^{1}$, S Rosas ${ }^{1}$, NT Britton ${ }^{1}$, EA Hothem ${ }^{1}$, KR Chin ${ }^{2,3,4}$, A Simela ${ }^{5}$
}

\begin{abstract}
Objective: Neck pain is a leading cause of disability with an increased prevalence of up to $20 \%$ annually in some reports. Various studies have shown improvements in symptoms and quality of life in patients who underwent anterior cervical discectomy and fusion (ACDF) for symptomatic nerve root compression and spondylosis. With the increased prevalence of these aforementioned conditions, it is imperative to understand the national trends in the use of ACDF. The authors aim to report on the incidence of ACDF in the United States of America (USA) over a four-year period and the associated procedural reimbursement costs.

Methods: A query was performed for patients who underwent ACDF using the PearlDiver supercomputer (Warsaw, IN) from 2011 to 2014. Patients were identified by current procedural terminology (CPT) Codes 22551 and 22552 and their demographics, location of surgery and reimbursement costs were later analysed.

Results: Our query returned a total of 13143 ACDFs over the four-year study period of 2011 to 2014. The total number of procedures done in the outpatient setting increased significantly from 454 in 2011 to 815 in 2014 ( $\mathrm{p}=0.005$ ); whereas those in the hospital setting did not from 1986 in 2011 to 2925 in $2014(\mathrm{p}=0.118)$. Of the total amount of surgeries, $10.556(80.4 \%)$ were performed in the hospital setting compared to 2587 performed in the ambulatory surgical centre [ACS: outpatient setting] ( $\mathrm{p}<0.001$ ). The four-year mean reimbursement cost for ACDF done in the inpatient setting was $\$ 2407.75$ compared to $\$ 5014$ in the outpatient setting, which was not statistically significant $(\mathrm{p}=0.36)$.

Conclusion: Over the four-year study period, the total number of ACDF performed in the outpatient setting increased significantly. There was no difference in the mean reimbursement according to the location where the surgery was performed $(\mathrm{p}=0.36)$.
\end{abstract}

Keywords: Anterior cervical discectomy and fusion, cervical, economic analysis, epidemiology, national sample, neck pain

\section{Tendencias en la discectomía y fusión cervical anterior ambulatoria frente a la intrahospitalaria en los Estados Unidos de América: un análisis epidemiológico y económico}

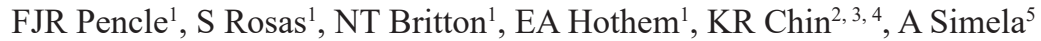

\begin{abstract}
RESUMEN
Objetivo: El dolor de cuello es la principal causa de discapacidad, con un aumento de su prevalencia de hasta un $20 \%$ anualmente según algunos reportes. Varios estudios han mostrado mejoras en los sintomas y la calidad de vida en pacientes sometidos a discectomía y fusión cervical anterior (DFCA) debido a espondilosis y compresión sintomática de la raíz del nervio. Con la mayor prevalencia de las condiciones mencionadas, resulta imperativo entender las tendencias nacionales en el uso de ACDF.
\end{abstract}

From: ${ }^{1}$ Less Exposure Surgery (LES) Society, USA, ${ }^{2}$ Charles E Schmidt College of Medicine at Florida Atlantic University, USA, ${ }^{3}$ Herbert Wertheim College of Medicine at Florida International University, USA, ${ }^{4}$ Less Exposure Surgery Specialists Institute (LESS Institute), USA and ${ }^{5}$ Bronx-Lebanon Hospital Center, USA.
Correspondence: Dr K Chin, Less Exposure Surgery Specialists Institute (LESS Institute), 1100 W. Oakland Park Blvd. Suite \#3, Fort Lauderdale, FL, 33311, USA. Email: kingsleychin@thelessinstitute. com 
Los autores tienen por objeto informar sobre la incidencia de la DFCA en los Estados Unidos de América (EE.UU.) en un periodo de siete años, y los costos de reembolso asociados con los procedimientos.

Métodos: Se realizó una pesquisa de pacientes que fueron sometidos a DFCA usando la supercomputadora PearlDiver (Warsaw, IN) desde 2011 a 2014. Los pacientes fueron identificados mediante los códigos 22551 y 22552 de la terminología actualizada de procedimientos médicos (CPT, siglas en inglés), y la demografia, lugar de la cirugía y los costos de reembolso fueron analizados posteriormente.

Resultados: Nuestra pesquisa arrojó un total de 13143 procedimientos de DFCA durante un período de estudio de cuatro años, de 2011 al 2014. El número total de procedimientos realizados en un contexto ambulatorio aumentó significativamente de 454 en 2011 a 815 en 2014 ( $\mathrm{p}=0.005)$, a diferencia del contexto hospitalario, de 1986 en 2011 a 2925 en 2014 ( $\mathrm{p}=0.118)$. Del total de cirugías, 10.556 $(80.4 \%)$ se realizaron en un contexto de hospitalización, en comparación con las 2587 realizadas en el centro de cirugías ambulatorias [CCA: contexto ambulatorio] (p \&lt; 0.001). El costo de reembolso promedio de procedimientos de DFCA realizados de forma intrahospitalaria en cuatro años, fue de \$2407.75 en comparación con \$5014 en el contexto ambulatorio, que no fue estadísticamente significativo $(\mathrm{p}=0.36)$.

Conclusión: Durante el período de estudio de cuatro años, el número total de procedimientos de DFCA realizados de forma ambulatoria, aumentó significativamente. No hubo diferencias en el reembolso promedio con respecto al lugar donde se realizó la cirugía $(\mathrm{p}=0.36)$.

Palabras claves: discectomía y fusión cervical anterior, cervical, análisis económico,epidemiología, muestreo a nivel nacional, dolor de cuello

West Indian Med J 2017; 66 (3): 400

\section{INTRODUCTION}

Anterior cervical discectomy and fusion (ACDF) has been a standard of practice in the United States of America (USA) since the early 1950s (1). This is a simple and safe procedure performed to achieve cervical nerve root and spinal cord decompression at a low complication rate, low postoperative morbidity, and high fusion rate (2). Various techniques $(3,4)$ have been developed to perform this procedure and as time evolves newer techniques and devices are employed in order to try to obtain better patient outcomes.

The transition from patients being admitted to hospital (inpatient) ACDF procedures being performed on a same day (outpatient) setting over the past two decades has been on the increase due to many factors (5). Some factors of the transition towards the outpatient setting include, reducing costs, minimally invasive approach usage, and/or increasing allograft usage (6). There has also been decreased time in on-site facility locations, shorter return home times, advancement in outpatient surgical centres, and advancement in surgical techniques, which are methods favoured by physicians and patients (7).

Recent studies have shown that an inpatient ACDF procedure can cost anywhere from $\$ 6700$ to $\$ 15000$, yielding $\$ 4000$ to $\$ 8000$ in savings by operating in an outpatient setting (7).

Various studies $(2,6,8,9)$, have stated that performing ACDF in the outpatient setting can provide satisfactory outcomes but currently, there is no study in the literature to the authors' knowledge that analyses the trends of patient use in each location for ACDF in a national sample. The purpose of this study was to report on the incidence of ACDF, in the USA over a recent four-year period (2011-2014), the associated procedural reimbursement costs associated with the inpatient and the outpatient setting and the demographic distribution of the surgeries. We also intended to compare the groups of patients according to the location of surgery inpatient versus outpatient as to better understand which factors might be directing patients to the outpatient setting.

\section{SUBJECTS AND METHODS}

A survey was conducted of unidentified patient records within the PearlDiver Database (PearlDiver Inc, Warsaw, Indiana) for the years 2011 through 2014. The search was performed through the use of current procedural terminology (CPT) codes 22551 and 22552 for ACDF. Data were stratified to create two groups according to where the surgery was performed. The first group was that of those patients who underwent surgery in the inpatient setting and the second group was of those who were operated in as outpatient setting. The PearlDiver Database is a publicly available. Health Insurance Portability and Accountability Act (HIPAA)-compliant national database compiled from a collection of private insurer records. This query was performed within the Humana database, which holds more than two billion individual patients. The PearlDiver Supercomputer has been previously used in an array of studies and provides medical procedure data for analysis looking at outcomes, cost of procedures and reimbursements (10-12).

In addition to CPT and ICD-9 codes, demographic data such as; age and gender were also recorded and analysed. Data 
were analysed using the SPSS statistical software version 22 (IBM Corp, New York, USA). Kolmogorov-Smirnov (13) testing was performed to analyse if the age groups had a Gaussian distribution. Correlational analysis was conducted using linear regression to assess the trends in ACDF from 2011 to 2014. Analysis of variance (ANOVA) and the student $t$-test were used for analysis where appropriate. Tests were considered significant if $p<0.05$.

\section{RESULTS}

The database contains more than 56 million patient records. Within the study period, there were a total of 30803241 patients in the dataset available for scrutiny. There were a total of 13143 ACDFs performed within the study period. Of which, 10506 were performed in the inpatient setting, while 2587 were performed in the outpatient setting $(p<0.001)$. The patient demographics are presented in Table 1 .

Table 1: Patient demographics

\begin{tabular}{lcc}
\hline Age (years) & Inpatients & Outpatients \\
\hline 20 to 24 & 12 & -1 \\
25 to 29 & 22 & 13 \\
30 to 34 & 90 & 49 \\
35 to 39 & 199 & 156 \\
40 to 44 & 446 & 257 \\
45 to 49 & 770 & 342 \\
50 to 54 & 1196 & 410 \\
55 to 59 & 1388 & 396 \\
60 to 64 & 1340 & 295 \\
65 to 69 & 2186 & 311 \\
70 to 74 & 1656 & 232 \\
75 to 79 & 825 & 72 \\
80 to 84 & 282 & 32 \\
85 to 89 & 62 & -1 \\
90 and over & 23 & -1 \\
\hline
\end{tabular}

The mean age of patients in the inpatient group was $58 \pm$ 8 and $58 \pm 7$ years in the outpatient group. There were 5448 females in the inpatient setting (52\%), whereas the outpatient setting had 1305 females (50\%). The total number of ACDF procedures done in the inpatient setting did not change significantly from 1986 in 2011 to 2925 in 2014 ( $p=0.118)$. In contrast to this, the total number of ACDF procedures done in the outpatient setting increased significantly from 454 in 2011 to 815 in $2014(p=0.005)$. The regional distribution of the procedures is shown in Table 2. The South was the region where the majority of surgeries were performed in both settings.

The annual incidence of ACDF in the inpatient setting went from $0.030 \%$ in 2011 to $0.032 \%$ in 2014 , which did not prove to be a statistically significant difference $[p=0.709]$ (Table 3 ).
Table 2: Regional distribution of surgeries

\begin{tabular}{lcc}
\hline Region & Inpatients & Outpatients \\
\hline Midwest & $19.7 \%$ & $23.26 \%$ \\
Northeast & $1.6 \%$ & $1.05 \%$ \\
South & $69.1 \%$ & $71.06 \%$ \\
West & $9.6 \%$ & $4.63 \%$ \\
\hline
\end{tabular}

Table 3: Inpatient procedural utilization

\begin{tabular}{lcll}
\hline Year & Patients & Incidence & $\begin{array}{l}\text { Incidence per } \\
\mathbf{1 0 0} \mathbf{0 0 0}\end{array}$ \\
\hline 2011 & 1986 & $0.030 \%$ & 30.34878641 \\
2012 & 2538 & $0.035 \%$ & 35.18377631 \\
2013 & 3107 & $0.039 \%$ & 39.37388552 \\
2014 & 2925 & $0.032 \%$ & 31.95061625 \\
\hline
\end{tabular}

The annual incidence of outpatient ACDF went from $0.007 \%$ in 2011 to $0.009 \%$ in 2014 , which did not prove to be a statistically significant difference [0.119] (Table 4).

When comparing costs, the average inpatient reimbursement for inpatient ACDF began at \$2458 in 2011 and ended at $\$ 2380$ in 2014. In contrast, for outpatient ACDF, the average reimbursement began at $\$ 4836$ dollars in 2011 and ended at $\$ 5283$ in 2014 (Table 5).

Table 4: Outpatient procedural utilization

\begin{tabular}{lccl}
\hline Year & Patients & Incidence & $\begin{array}{l}\text { Incidence per } \\
\mathbf{1 0 0 ~ 0 0 0}\end{array}$ \\
\hline 2011 & 454 & $0.00694 \%$ & 6.937738685 \\
2012 & 604 & $0.00837 \%$ & 8.3731288 \\
2013 & 714 & $0.00905 \%$ & 9.048263361 \\
2014 & 815 & $0.00890 \%$ & 8.902479401 \\
\hline
\end{tabular}

The four-year mean reimbursement cost for ACDF done in the inpatient setting was $\$ 2407.75$ compared to $\$ 5014$ in the outpatient setting, which was not statistically significant $(p=0.36)$. Correlation analysis performed between reimbursements and number of procedures demonstrated no significance in both groups, $\mathrm{R}=0.404, p=0.596$ in the inpatient cohort and $\mathrm{R}=0.652, p=0.348$ in the outpatient cohort.

Table 5: Average yearly mean reimbursement

\begin{tabular}{lll}
\hline Year & $\begin{array}{l}\text { Inpatient mean } \\
\text { reimbursement }\end{array}$ & $\begin{array}{l}\text { Outpatient mean } \\
\text { reimbursement }\end{array}$ \\
\hline 2011 & $\$ 2458$ & $\$ 4836$ \\
2012 & $\$ 2363$ & $\$ 5091$ \\
2013 & $\$ 2430$ & $\$ 4846$ \\
2014 & $\$ 2380$ & $\$ 5283$ \\
Mean & $\$ 2407.75$ & $\$ 5014$ \\
\hline
\end{tabular}




\section{DISCUSSION}

The study aimed to determine the trend of ACDF as it relates to the total number of procedures performed nationally as well as the operative settings thereof. Overall, there was a statistical increase in the total number of procedures being performed in the outpatient setting. Based on analysis, the number of procedures performed in the inpatient and outpatient cohort is not directly correlated to reimbursements. This study showed higher reimbursements cost in the outpatient setting although no significance was demonstrated. However, this does not correlate to published data; a study by Silvers et al demonstrated the safety and efficacy of ACD in the outpatient setting with an estimated \$100 million annual economic savings (14). Other factors leading to increase in ACDF procedures being performed in the outpatient setting can be attributed to better outcomes and quality of life $(2,5,15)$.

There has been a growing interest in spine surgery being performed in the outpatient setting. Currently, there is in excess of 6000 outpatient centres in operation in the USA (16). The literature is satiated with data on the epidemiology and outcomes of spine operation in a hospital-based setting (17-21).

Several stuies have demonstrated good outcome, excellent safety levels of outpatient ACDF to inpatient ACDF and an approimated $2 \%$ complication rate $(2,6-9,15)$. Additional, studies have also demonstrated the cost-effectiveness of $\operatorname{ACDF}(5,14,22,23)$. Carreon et al demonstrsted that ACDF had a favourable five-year cost per adjusted quality of life year (23). The associated improved outcomes and decreased cost to patient are factors leading to an increase trend in ACDF being performed in the outpatient setting.

\section{Limitations}

This study is not without limitations. The PearlDiver Database is reliant upon accurate CPT or international classification of diseases (ICD) coding which creates the potential for a reporting bias. The sample size based on database is only of insurance based users and would not include cash paying patients.

\section{Strengths}

One of the strengths of this study is the large patient population that was analysed. In addition, the study adds to the body of knowledge as it relates to outpatient ACDF, as it investigates the rate of surgery incidence in the outpatient setting and associated cost reimbursement, which has not been adequately studied previously.

\section{CONCLUSION}

The results of this study have shown a statistically significant increase in the amount of ACDF procedures being performed in the outpatient setting. The increase in outpatient procedures may be due to decreased complications and quicker return to activity. There was no significant difference in reimbursement cost on national average, demonstrating that financial gain was not a contributing factor to patient procedures being performed in the outpatient setting. The preferences for outpatient surgeries are on the rise not only by physicians, but also by patients due to social and economic advantage and short operational time.

\section{AUTHORS' NOTE}

Conflicts of interest and sources of funding: We did not seek or receive any funding from the National Institutes of Health (NIH), Wellcome Trust, Howard Hughes Medical Institute (HHMI), or others for this work. Dr KR Chin, is a shareholder in and receives other benefits from SpineFrontier Inc. None of the other authors (FJRP, SM, NTB, EAH and AS) or any member of his or her immediate family has funding or commercial associations (eg, consultancies, stock ownership, equity interest, patent/licensing arrangements, etc) that might pose a conflict of interest in connection with the submitted article. The manuscript submitted does not contain information about medical device(s)/ drug(s).

\section{REFERENCES}

1. Le H, Thongtrangan I, Kim DH. Historical review of cervical arthroplasty. Neurosurg Focus 2004; 17: E1.

2. Erickson M, Fites BS, Thieken MT, McGee AW. Outpatient anterior cervical discectomy and fusion. Am J Orthop 2007; 36: 429-32.

3. Robinson RA, Smith GW. Anterolateral cervical disc removal and interbody fusion for cervical disc syndrome. Bull John Hopkins Hosp 1955; 96: $223-4$.

4. Cloward RB. The Anterior Approach for Removal of Ruptured Cervical Disks. J Neurosurg 1958; 15: 602-17.

5. McGirt MJ, Godil SS, Asher AL, Parker SL, Devin CJ. Quality analysis of anterior cervical discectomy and fusion in the outpatient versus inpatient setting: analysis of 7288 patients from the NSQIP database. Neurosurg Focus 2015; 39: E9.

6. Liu JT, Briner RP, Friedman JA. Comparison of inpatient vs. outpatient anterior cervical discectomy and fusion: a retrospective case series. BMC Surg 2009; 9: 3.

7. Tally WC, Tarabadkar S, Kovalenko BV. Safety and feasibility of outpatient ACDF in an ambulatory setting: A retrospective chart review. Int J Spine Surg 2013; 7: e84-7.

8. Sheperd CS. Instrumented Outpatient Anterior Cervical Discectomy and Fusion: Is it Safe? 2012; 97: 86-9.

9. Trahan J, Abramova MV, Richter EO, Steck JC. Feasibility of anterior cervical discectomy and fusion as an outpatient procedure. World NeuroSurg 2011; 75: 145-8.

10. Ackermann J, Fraser EJ, Murawski CD, Desai P, Vig K, Kennedy JG. Trends of concurrent ankle arthroscopy at the time of operative treatment of ankle fracture: a national database review. Foot Ankle Spec 2015; 9: 107-12.

11. Rosas S, Law TY, Kurowicki J, Formaini N, Kalandiak SP, Levy JC. Trends in surgical management of proximal humeral fractures in the Medicare population: a nationwide study of records from 2009 to 2012. J Shoulder Elbow Surg 2015; 25: 608-13.

12. McCormick F, Nwachukwu BU, Kiriakopoulos EB, Schairer WW, Provencher MT, Levy J. In-hospital mortality risk for total shoulder arthroplasty: A comprehensive review of the medicare database from 2005 to 2011. Int J Shoulder Surg 2015; 9: 110-3.

13. Grover NB. Two-sample Kolmogorov-Smirnov test for truncated data. Comput programs biomed 1977; 7: 247-50.

14. Silvers HR, Lewis PJ, Suddaby LS, Asch HL, Clabeaux DE, Blumenson LE. Day surgery for cervical microdiscectomy: is it safe and effective? J Spinal Disord 1996; 9: 287-93. 
15. Villavicencio AT, Pushchak E, Burneikiene S, Thramann JJ. The safety of instrumented outpatient anterior cervical discectomy and fusion. Spine J 2007; 7: 148-53.

16. Homsted L. Institute of Medicine report: to err is human: building a safer health care system. Fla Nurse 2000; 48: 6 .

17. Powell ETt, Krengel WF, 3rd, King HA, Lagrone MO. Comparison of same-day sequential anterior and posterior spinal fusion with delayed two-stage anterior and posterior spinal fusion. Spine 1994; 19: 1256-9.

18. Haher TR, Merola A, Zipnick RI, Gorup J, Mannor D, Orchowski J. Meta-analysis of surgical outcome in adolescent idiopathic scoliosis. A 35-year English literature review of 11,000 patients. Spine 1995 20: $1575-84$.

19. Rosenfeld HE, Limb R, Chan P, Fitzgerald M, Bradley WP, Rosenfeld $\mathrm{JV}$. Challenges in the surgical management of spine trauma in the morbidly obese patient: a case series. J Neurosurg Spine 2013; 19: 101-9.
20. Nuno M, Drazin DG, Acosta FL, Jr. Differences in treatments and outcomes for idiopathic scoliosis patients treated in the United States from 1998 to 2007: impact of socioeconomic variables and ethnicity. Spine J 2013; 13: 116-23.

21. Nandyala SV, Marquez-Lara A, Fineberg SJ, Singh K. Comparison between cervical total disc replacement and anterior cervical discectomy and fusion of 1 to 2 levels from 2002 to 2009. Spine 2014; 39: 53-7.

22. Adamson T, Godil SS, Mehrlich M, Mendenhall S, Asher AL, McGirt MJ. Anterior cervical discectomy and fusion in the outpatient ambulatory surgery setting compared with the inpatient hospital setting: analysis of 1000 consecutive cases. J Neurosurg Spine 2016; 1-7.

23. Carreon LY, Anderson PA, Traynelis VC, Mummaneni PV, Glassman SD. Cost-effectiveness of single-level anterior cervical discectomy and fusion five years after surgery. Spine 2013; 38: 471-5. 